\title{
INDICAÇÃO ANESTESICA PARA O TRATAMENTO DOS FRATURADOS DA FACE
}

\section{SINOPSE}

A anestesia para tratamento das fraturas maxilo-faciais independe da técnica utilizada, mas deve ser sufï ciente para dar o confôrto devido ao สิoente e ao cirurgião。

Com frequiência a anestesia local é usada para as pequenas fraturas da mandíbula e do maxilar em pacientes lúcidos e cooperantes. O método de preferência é sempre a anestesia troncular. Nas críanças, adultos pusilânimes, emotivos e nos psicopatas a anestesia geral é obrigatória. Sem dúvida a anestesia geral tem indicação precisa em tôdas as grandes fraturas faciais sobretudo quando existem fraturas associadas ou em politraumatizados. A entubação traqueal é indispensável, resguardando-se as técnicas de traqueotomia para os ca-

\author{
Onofre Sampaio Cavalcante \\ Anestesista da Casa de Saúde César \\ Cals e do Sanatório de Messejena - \\ INPS.
}

sos em que a lesão facial afeta regiões de interêsse para a entubação. As manobras de reanimação; tratamento do choque, hemorragia e permeabilidade da via respiratória foram citadas porque devem ser adotadas e têm precedência sôbre o tratamento da lesão facial.

o tratamento cirúrgico das fraturas dos ossos da face podem ser executadas sob três tipos de anestesia: anestesia local, anestesia geral e anestesia mista, ou seja, associação de anestesia local com anestesia geral. A escolha do método anestésico irá depender de vários fatôres, considerando-se: localização, tipos, extensão, grau de lesão das partes moles, estado geral, emergência cirúrgica, idade e psiquismo do paciente.

o exame geral e a avaliação da lesão facial condicionarão o tratamento e a indicação anestésica. As

(Parte integrante do simpósio sôbre Traumatologia Maxilo-Facial realizado no 19 Congresso de Patologia e Cirurgia Buco-Facial, em Fortaleza à 23/29 de novembro de 1969). 
fraturas maxilo-faciais constituem sempre uma situação de urgência que exige tratamento e cuidados especiais que lhes são inerentes. Por se tratar de urgência, o risco anestésico é sempre um agravante que deve ser avaliado. Nesse particular, devemos recordar que qualquer paciente a ser anestesiado em situação de emergência', é considerado como paciente de «estômago cheio». Os fraturados de face, geralmente, vítimas de acidentes de veículos, além da possibilidade de plenitude gástrica, apresentam-se com hemorragia copiosa que pode ser aspirada ou deglutida. Observa-se obstrução das vias aéreas superiores por queda da língua, edema, sangue, dentes ou aparêlhos de prótese quebrados e salivação abundante.

Quando o traumatismo se restringe a pequenas fraturas dos ossos da face e o paciente encontra-se consciente e cooperante, a anestesia 1ocal pode ser usada com vantagens. Ao contrário nos politraumatizados inconscientes ou nos grandes traumatismos faciais com, lacerações extensas, afundamento do maciço facial, a anestesia geral é a indicada.

Dos métodos de anestesia local, a troncular ou bloqueio anestésico dos ramos colaterais ou terminais do trigêmio tem sido o método de preferência dos cirurgiões plásticos, rinologistas e odonto-estomatologistas.

Os bloqueios tronculares possuem propriedades deveras interessantes:

1. A injeção de pequenas doses de anestésico permite insensibilizar um extenso território da hemi-face.
2. Não modifica as condições tissulares locais já que o anestésico é injetado à distâcia da zona lesada.

3. E dé técnica relativamente fácil para aquêles que estão familiarizados com o método como é o caso dos especialistas em cirurgia maxilo-facial.

4. Permite intervir sôbre pacientes conscientes.

5. Proporciona campo mais exangue em relação a anestesia geral.

6. É menos tóxica.

7. Não interfere nos reflexos de tosse e deglutição e dessa forma impede a aspiração de sangue ou vômitos durante a intervenção, causa principal de óbitos na indução da anestesia geral.

8. Não condiciona vômitos no pós-operatório.

A anestesia local, entretanto, pode dar lugar a acidentes indesejáveis, por vêzes dramáticos e mortais. Daí a necessidade de um interrogatório prévio sôbre as possíveis reações apresentadas pelo paciente em anestesias anteriores ou ao uso de medicamentos contendo anestésicos locais. A prudência manda que se injete o anestésico lentamente e que se observe as reações do paciente.

O aparecimento de dispneia, opressão torácica, palidez, cianose, taquicardia, obriga a suspensão da injeção. Infelizmente na maioria dos casos os acidentes surgem de maneira brutal, sem prodromos, com convulsões generalizadas e colapso cárdio- 
respiratório. Sempre que se aplicar uma anestesia local convém ter à mão, para emprêgo imediato em caso de necessidade um tiobarbiturato, um relaxante muscular "de ação breve, material para entubação traqueal e respiração controlada. Em caso de parada cardíaca instituir a massagem cardíaca.

A anestesia local associada a uma bôa sedação de base, proporciona uma anestesia suficiente que permite a realização da maioria das operações maxilo-faciais. A grande inconreniência do método consiste em ser desagradável ao paciente obrigandonos muitas vêzes a aumentar a quantidade de medicação sedativa para que êle se torne cooperante. Constituem contra- indicações formais sua administração em crianças e adultos pusilânimes ou em psicopatas que por razões óbvias não conseguem permanecer tranquilos durante a execução do ato cirúrgico. Acreditamos que a anestesia local deve ser reservada para as pequenas fraturas alveolares, algumas da mandíbula e do malar em pacientes conscientes e cooperantes. Fora dessas circunstâncias se elegerá a anestesia geral com entubação endotraqueal.

E fato conhecido que as fraturas dos ossos da face raramente são fatais, entretanto as complicações secundárias de obstrução respiratória, hemorragia e choque constituem situações de emergência que podem tornar-se letais se não corrigidas com presteza antes mesmo do tratamento da fratura. Os grandes traumatismos faciais como a disjunção crâneo-encefálica tipo de Le Fort III e as fraturas bilaterais da mandibula com deslocamento posterior levando a língua para trás obstruindo a via respiratória, impõem assistência médica imediata no próprio local do acidente. A simples colocação de um tubo naso-faringeo muitas vêzes salva o paciente de uma morte certa por asfixia. Keneth Lewis referindo-se ao paciente, que se apresenta com a bôca cheia de sangue, edemaciado e asfictico, disse: «Quanto mais êle olha para Deus mais cêdo o verá», o que vale dizer que a posição supina pode matar por asfixia. É necessário que se faça uma limpeza imediata do orofaringeo e o transporte do paciente para o hospital em posição prona com a cabeça voltada para o lado, o que facilita a drenagem das secreções e melhora a permeabilidade da via aérea. Os cuidados médicos imediatos consistem em apoiar a respiração e a circulação e nas manobras de reanimação quando se fizerem necessárias.

o exame das condições locais da lesão indicarão a necessidade ou não da traqueotomia. Nas fraturas dos ossos nasais em conjunção com as do maxilar ou do mandibular com obstruẹão respiratória, realiza-se a traqueotomia de urgência. A anestesia geral será então realizada pela cânula do traqueotoma.

As técnicas de anestesia geral têm progredido bastante nos últimos anos, de tal sorte que, o campo de ação da mesma vem aumentando muito no tratamento cirúrgico das lesões maxilo-faciais.

Em traumatologia tôdas as fraturas maxilo-faciais podem ser tratadas sob anestesia geral. Ela tem indicações precisas em todos os casos 
que contraindicam a anestesia local, nos etilistas, nos cardíacos descompensados e principalmente nos politraumatizados onde o conjunto de lesões requer cuidados imediatos e pode ser tratado no mesmo ato anestésico. E executada exclusivamente em ambiente hospitalar e por médico especialista.

A anestesia géral em traumatologia maxilo-facial deve possuir as seguintes condições essenciais:

a) Indução rápida

b) Ser realizada sob entubação traqueal

c) Anestesia suficiente

d) Despertar precoce

e) Ausência de complicações secundárias, imediatas ou tardias.

Atualmente com o emprêgo dos anestésicos voláteis fluorinados, neurolépticos e analgésicos, dos miorrelaxantes de ação breve, consegue-se rapidez na indução e facilidade no ato da entubação traqueal. Nos grandes traumatismos maxilo-faciais, por vêzes, em conseqüência do trismo usa-se a entubação naso-traqueal cega. Quando há dificuldade na passagem cega da sonda naso-traqueal pode-se lançar mão da manobra de Powell e Ozdil onde um cateter plástico servirá de guia após sua introdução em direção orofaríngea através da membrana cricotireóide por intermédio de um «Intracath».

Das complicações secundárias imediatas temos a considerar a broncoaspiração de vômitos, sangue ou secreções e o aumento do sangramento no campo operatório. A entubação deve ser praticada com o paciente acordado com os reflexos de tosse $t$ deglutição diminuidos. A neuroléptoanalgesia facilita muito a entubação traqueal porque acalma o paciente deixando-o em estado de indiferença psíquica e permite a entubação traqueal sem anestesia tópica e sem necessidade de relaxantes musculares.

o sangramento no campo operatório é reconhecidamente maior na anestesia geral. As técnicas de hipotensão induzida com ganglioplegia podem ser empregadas, porém são perigosas e agravam o risco cirúrgico. O emprêgo do fluotano e a posição proclivo usada em cirurgia maxilo-facial diminue $o$ sangramento operatório sem os inconvenientes da hipotensão induzida. Ainda com a finalidade de diminuir o sangramento no campo operatório pode ser empregada a associação de anestesia geral com antestesia local. Nesse particular devemos chamar atenção sôbre o uso das vasoconstrictores que sensibilizam o miocárdio aos agentes halogenados, podendo promover fibrilação ventricular. Quando houver necessidade dessa associação empregar agentes compatíveis com os adrenérgicos. A neuroléptoanalgesia clássica permite essa associação.

Duas complicações pós-operatórias são temidas em cirurgia maxilo-facial: a excitação ao despertar capaz de comprometer o êxito cirúrgico e os vômitos pós-operatórios que pođem originar acidentes de asfixia em pacientes com o mandibular imobilizado. A agitação deve-se à dôr e à imobilização incômoda nas fraturas. Para evitá-la é necessária sedação operatória residual eficiente e o retôrno imediato da consciência. 
A neuroléptoanalgesia parece ser o método mais apropriado para sanar êsses inconvenientes. Promove boa analgesia residual, recuperação precoce da consciência, estado de indiferença psíquica, pequena, incidência de vômitos pós-operatórios. Qualquer método de anestesia geral, entretanto, pode ser utilizado desde que se faça uma sedação pós-operatória eficiente e a profilaxia dos vômitos. A metoclopramida, atualmente é a droga de preferência na profilaxia dos vômitos pós-operatórios. Atua por mecanismo central na zona «trigger»e não determina efeitos colaterais indesejáveis.

\section{SYNOPSIS}

The anesthesia for the treatment of maxilo-facial fractures should be good enough to the confort of the patient and assuring a quite operating field for the surgeon.

Regional anesthesia is often used in the treatment of small fractures of the bones of the face.

In children and non cooperative adults the general anesthesia is mandatory. In the great injuries of the face and in patients with multiple trauma the general anesthesia is the best. choice. The orotraqueal entubations must be always performed and the traqueostomy should be done only in cases where the facial inju. ry do not allow the orotraqueal entubations.

In this brief discussion we also call attention for some points in general case of the patient such as treatment of the shock, respiratore failure and problems related.

\section{REFERÊNCIAS BHBLIOGRÁFICAS}

1. AUBry, M \& FREIDEL, C. Chirurgie de la face et de la région maxillo-faciale Paris, Masson, 1952. 879p.

2. BANKOFF - La practica de la anestesia local.|s.1.| Hachette, 1958.

3. CASEY, E. D. Tratamento das fraturas do maxilar superior e da mandíbula.

4. CREMONESI, E. Contribuição para o estudo da neuroloeptoanalgesia tipo II. Tese de doutoramento F.M.C.S.P. São Paulo, 1964.

5. FREY, R. Tratado de anestesiologia. |s.1.| Salvat, 1960.

6. GRAZIANI, M. Cirurgia buco-maxilar. 4. ed. Rio de Janeiro, Científica, 1958.

7. KAZANJIAN, V. H. \& CONVERSE, S. M. The Surgical treatment of facial injuries. Baltimore, Wilkins, 1959.

8. KOFF, V. J. \& MICKELBERG, A. Mietoclopramida na prevenção de vômitos e náuseas pós anestésicas. Rev. Bras. Anest. Rio de Janeiro, 18(2):209-16. 1968.

9. LEE, A. J. A Synopsis of anesthesia. Bristol, Wright, 1959.

10. MAROTTE, R. Elèments d'anesthesia; programmes de études de 
chirurgie dentaires. Paris, Gilbert $\mid$ s.d.|

11. MOSEley, F. H. Accident surgery. New York, A.C.C., 1962, v.1.

12. MENDES, M. C. Acidentes e complicaçõ ${ }^{\prime}$ s na entubação traqueaĩ.

Rev. Bras. Anest. Rio de Janeiro, 17(3):298-313. jul.-set. 1967.

13. NEWLANDS, C. Anestesia odontológica. 2.ed. Rio de Janeiro, Científica, 1946. $158 \mathrm{p}$.

14. OWENS, N. Y. \& GORNEY, M. Immediate treatment of traumatic injuries.

15. PORTMANN, G. et alii -- Anesthesia in oto-rhino-laringologie. Paris, G.' Doin, 1956.

16. POWELL, Ozdil. A translaryngeal guide for tracheal intubation. Anesth. Analg. Cleveland, 46(2):231-4, 1967.

17. QUEINNEC, J. L.: Anesthésie générale en stomalogie. Anesth. Analg., Cleveland, 2:247-360. mar./abr. 1956.

18. REES, T. D. The immediate management of severe maxilo-facial injuries. Surg. Clin. N. Amer... Philadelphia, 39: 379-391, 1959.

19. RICHARDS, H. J. Respiratory obstructions from fractures of the jaw. Brit. Med. J. London, 1:1113, 1950.

20. ROWE, N. L. \& KILLEY, H. C. Fractures of the facial sheleton. Edinburg, Livingstone, 1955.

21. RUSSO, R. o paciente com estômago cheio. Rev. Bras. Anest., Rio de Janeiro, 17(4) : 356-364, 1967. 